\title{
Structural investigation of platinum solubility in silicate glasses
}

\section{François FArges, ${ }^{1, *}$ DANiel R. NEUVILle, ${ }^{2}$ ANd Gordon E. BRown JR. ${ }^{3}$}

\author{
${ }^{1}$ Laboratoire des géomatériaux, Université de Marne-la-Vallée, 77454 Marne-la-Vallée Cedex 2, France \\ ${ }^{2}$ Laboratoire de physique des géomatériaux, CNRS and Institut de Physique du Globe de Paris, 4 place Jussieu, 75252 Paris Cedex 05, France \\ ${ }^{3}$ Department of Geological and Environmental Sciences, Stanford University and Stanford Synchrotron Radiation Laboratory, Stanford, \\ California 94305-2115, U.S.A.
}

\begin{abstract}
The coordination environment of 20-200 ppm Pt in yellowish glasses from the $\mathrm{CaO}-\mathrm{Al}_{2} \mathrm{O}_{3}-\mathrm{SiO}_{2}$ (CAS) ternary was studied using $\mathrm{X}$-ray absorption fine structure spectroscopy at the Pt- $\mathrm{L}_{\mathrm{III}}$ edge. Analysis of the Pt- $\mathrm{L}_{\text {III }}$ edge region suggests that $\mathrm{Pt}$ in these glasses is mainly tetravalent and sixfoldcoordinated by $\mathrm{O}$ (with a mean Pt-O distance of $2.08 \pm 0.02 \AA$ ). No evidence for $\mathrm{Pt}^{2+}$ or $\mathrm{Pt}^{6+}$ was found in any of the glasses studied, suggesting that one can not derive valence information easily from solubility data. No second-neighbor contribution was observed around $\mathrm{Pt}^{4+} \mathrm{O}_{6}$ polyhedra. However, bond-valence modeling suggest that these polyhedra are likely to bond mostly to ${ }^{[\mathrm{VI}]} \mathrm{Ca}^{2+}$, which should promote high positional disorder of second-neighbor cations around Pt. This particular bonding arrangement may explain the relatively high solubility of $\mathrm{Pt}$ in these relatively depolymerized melts, as $\mathrm{CaPtO}_{3}$-type units.
\end{abstract}

\section{INTRODUCTION}

Platinum is a strategic element that is relatively insoluble in oxide glasses (usually less than a few parts per million). However, for some silicate melts containing large amounts of alkaline-earth elements, it is possible to dissolve larger amounts of Pt (i.e., >10 ppm). The Pt found in some synthetic silicate glasses is derived from corrosion of Pt-crucibles by the melt (Fairbairn and Schairer 1952; Ginther 1971; Higby et al. 1990) which imparts a yellowish color to glasses richest in Pt. For example, in low-silica calcium aluminosilicate glasses/melts prepared at one atmosphere pressure, enhanced Pt solubility can be observed (Dablé 1996; Azif et al. 1996; Amossé et al., unpublished manuscript) and may be as high as $\sim 200 \mathrm{ppm}$ as observed here (Table 1). Based on indirect solubility and electrochemical measurements, the enhanced solubility of $\mathrm{Pt}$ in $\mathrm{CaO}-\mathrm{Al}_{2} \mathrm{O}_{3}-\mathrm{SiO}_{2}$ (CAS) melts under oxidizing conditions is related to the presence of oxidized valence states of Pt. Depending on the interpretation of experimental solubility data, $\mathrm{Pt}$ is thought to be in the +2 (Borisov et al. 1996) or +6 (Dablé 1996) valence state.

High Pt contents (above $100 \mathrm{ppm}$ ) are also observed in some oxide glasses used for nuclear waste storage (Kelm and Oser 1991; Pacaud et al. 1991). This Pt is generated by the decay of highly radioactive isotopes after storage for a few years. A better understanding of the structural factors that govern the enhanced solubility of $\mathrm{Pt}^{4+}$ in oxide glasses will help, for instance, to better extract this precious element from nuclear waste glasses.

\footnotetext{
*E-mail:farges@univ-mlv.fr
}

To explore the structural origin of the enhanced solubility of $\mathrm{Pt}$ in CAS melts, we have undertaken an X-ray absorption fine structure (XAFS) spectroscopy study of Pt in various yellowish glasses from the CAS system containing trace amounts (as low as $20 \mathrm{ppm}$ ) of Pt. XAFS spectroscopy was used to determine the oxidation state of $\mathrm{Pt}$ in these glasses as well as its coordination environment. In addition, bond-valence considerations were used to derive plausible models of the mediumrange structural environment around Pt in these glasses. Finally, structural information from this study was correlated with the solubility of $\mathrm{Pt}$ in these glasses/melts.

\section{EXPERIMENTAL DETAILS}

\section{Glass synthesis}

The nomenclature used to represent glass compositions here is $\mathrm{Ca}_{x, y}$ where $x$ and $y$ represent, respectively, the $\mathrm{mol} \% \mathrm{SiO}_{2}$ and $\mathrm{Al}_{2} \mathrm{O}_{3}$ components in the glass. The glasses were prepared by mixing reagent grade oxides $\mathrm{SiO}_{2}, \mathrm{Al}_{2} \mathrm{O}_{3}$, and $\mathrm{CaCO}_{3}$ in the desired amounts (Neuville 1992) (Fig. 1). The powders were slowly decarbonated at $1200 \mathrm{~K}$ and melted at $1900 \mathrm{~K}$ for 3-4 hours in a Pt crucible. The glasses were quenched from the melts by rapidly cooling the bottom of the crucible in water. The Pt present in the glasses derives directly from corrosion of the Pt-crucibles. In these glasses, the highest Pt contents were found in the most yellow glasses. Chemical analyses are in Table 1 .

\section{Pt-model compounds}

Various model compounds representative of the coordination chemistry of $\mathrm{Pt}$ were investigated, including: metallic $\mathrm{Pt}$, $\alpha-\mathrm{PtO}_{2}, \mathrm{Na}_{2} \mathrm{Pt}(\mathrm{OH})_{6}, \mathrm{~K}_{2} \mathrm{PtCl}_{6}$, and $\left(\mathrm{NH}_{4}\right)_{2} \mathrm{PtCl}_{6}$ (Bandel et al. 1979; Siegel et al. 1969; Takazawa et al. 1984). Metallic $\mathrm{Pt}^{0}$ 
TABLE 1. Chemical composition of the glasses studied (in wt\%)

\begin{tabular}{lllll}
\hline \hline Glass & $\mathrm{SiO}_{2}{ }^{*}$ & $\mathrm{Al}_{2} \mathrm{O}_{3}{ }^{*}$ & $\mathrm{CaO}^{*}$ & $\mathrm{Pt} \dagger$ \\
\hline $\mathrm{Ca}_{0,39}$ & $0.04(5)$ & $53.1(3)$ & $46.9(4)$ & 195 \\
$\mathrm{Ca}_{10,23}$ & $8.9(3)$ & $32.8(1)$ & $55.6(7)$ & 100 \\
$\mathrm{Ca}_{16.21}$ & $14.8(2)$ & $31.20(8)$ & $53.0(4)$ & $\approx 20$ \\
$\mathrm{Ca}_{10.35}$ & $8.2(8)$ & $49.9(6)$ & $42.6(5)$ & $\approx 50$ \\
\hline
\end{tabular}

Notes: Syntheses conducted in air and in platinum crucibles, run duration: 3-4 hours at $1900 \mathrm{~K}$.

*Electron-microprobe analyses done at the CAMPARIS, Paris. Data from

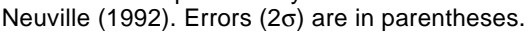

† Values in ppm (ICP analyses done at CRPG, Nancy, France).

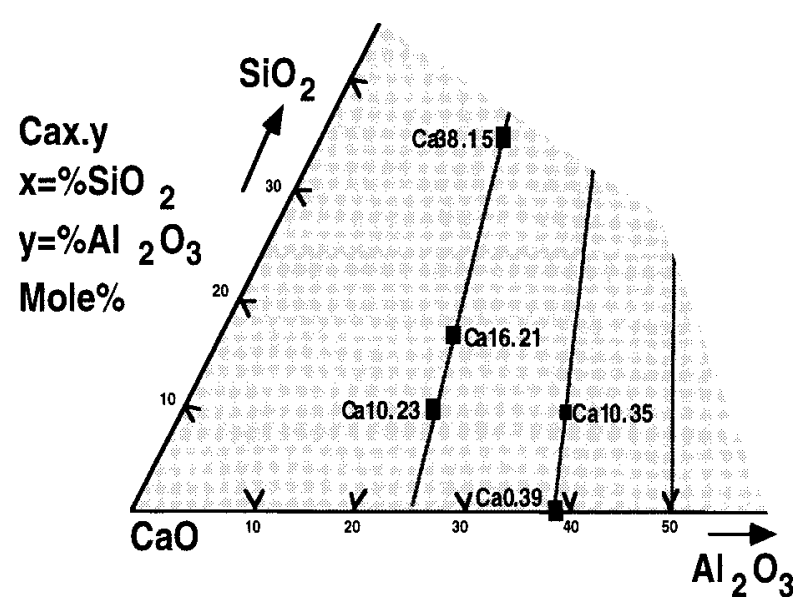

Figure 1. $\mathrm{CaO}-\mathrm{Al}_{2} \mathrm{O}_{3}-\mathrm{SiO}_{2}$ (CAS) ternary diagram showing the glass compositions studied.

represents the initial state of $\mathrm{Pt}^{0}$ prior to corrosion experiments. The four other reference compounds studied contain sixfoldcoordinated $\mathrm{Pt}^{4+}$, with either $\mathrm{O}$ or $\mathrm{Cl}$ first neighbors around $\mathrm{Pt}$. The average ${ }^{[\mathrm{VI}]} \mathrm{Pt}^{4+}-\mathrm{O}$ and ${ }^{[\mathrm{VI}]} \mathrm{Pt}^{4+}-\mathrm{Cl}$ distances are 2.00-2.06 and $\sim 2.30 \AA$, respectively.

\section{XAFS data collection}

Data were collected at the Stanford Synchrotron Radiation Laboratory on wiggler beam line IV-1 at the Pt $\mathrm{L}_{\mathrm{III}}$-edge (11.56 $\mathrm{keV})$. The storage ring operating conditions were $3 \mathrm{GeV}$ of electron energy and 30-100 mA of electron current. A Si-220 doublecrystal monochromator was used [energy resolution (FWHM) of $\sim 3 \mathrm{eV}$ at the $\mathrm{Pt}_{\mathrm{III}}$-edge for a beam width of $\sim 1 \mathrm{~mm}$ in the vertical direction; the $\mathrm{Pt} \mathrm{L}_{\mathrm{III}}$-edge core hole width is $\sim 5 \mathrm{eV}$ ]. Energy was calibrated using Pt metal foil. At all energies, the monochromator was detuned by $50 \%$ to eliminate higher energy harmonics in the incident X-ray beam. The incident- and transmitted-beam intensities were monitored with an ionization chamber, using Ar as the absorbing gas. Because self-absorption is unlikely to be a problem for $\mathrm{Pt}$ at these relatively low concentrations, absorbance was measured by monitoring fluorescence yield as a function of X-ray energy using a SternHeald-type detector with $\mathrm{Ar}$ in the fluorescence detector ion chamber. $\mathrm{A}_{2} \mathrm{O}_{3}$ filter (9 $\mu$ absorbance) was used to minimize unwanted fluorescence and scattered radiation. Because of the low Pt contents in the glass samples, XAFS spectra were obtained by averaging four to ten individual scans for each sample to improve the signal-to-noise ratio.

\section{XAFS data analysis}

Extended X-ray absorption fine structure (EXAFS) spectra were normalized in absorbance using a Victoreen and a spline function (with 10 external double knots, Winterer 1996). Energies were recalculated into $k$ space (where $k$ is the momentum of the photoelectron) with " $E_{0}$ " (i.e., the energy where $k$ is zero), arbitrarily chosen at the half-height of the absorption step (modeled with an arctangent function). The $k^{3}$-weighted EXAFS spectra were Fourier transformed (FT: Kaiser-Bessel type) over the $k$ range 2 to $10 \AA^{-1}$. The resulting modulus of the FT is a curve similar to a radial distribution function (RDF). However, the FT contains pair correlations involving only the central absorber (in this case Pt) and surrounding atoms and it is uncorrected for the phase-shifts of photoelectron waves as they interact with various surrounding atoms. The last step of data analysis consists of backtransforming the real and imaginary parts of the RDF (1-2.2 ̊ range). Modeling of these FT-filtered EXAFS oscillations using anharmonic and curved-wave theories (Crozier et al. 1988; Rehr et al. 1986) gives average structural parameters for the Pt environment: identity of firstneighbor atoms, average distance between $\mathrm{Pt}$ and these neighbors $(R)$, average number of first neighbors $(N)$, a Debye-Waller-type factor $\left(\sigma^{2}\right)$, and an anharmonic parameter $\left(C_{3}\right)$. The last two parameters provide a measure of relative disorder and anharmonicity of the Pt-O pair-correlation probed. Backscattering $\mathrm{O}$ amplitude and Pt-O phase-shift functions were calculated using the FEFF7 code (Zabinsky et al. 1995). Modeling of the normalized, raw EXAFS spectra could not be performed because of the presence of a multiple-scattering (MS) feature in the low-energy region of the spectra (particularly near $11590 \mathrm{eV}$ on Fig. 2), as will be demonstrated by X-ray absorption near edge structure (XANES) calculations (see below). This MS contribution adds a relatively intense peak in the FT (half that for Pt-O) near 2.5 $\AA$. It arises from multiple paths of the photo-electron inside the $\mathrm{PtO}_{\mathrm{n}}$ units involving the central Pt atom and two oxygen first neighbors (MS path of order 3).

\section{RESULTS}

Solubility of $\mathrm{Pt}$ is highest for glasses with Ca-rich compositions in the $\mathrm{CaO}-\mathrm{Al}_{2} \mathrm{O}_{3}-\mathrm{SiO}_{2}$ ternary (Table 1). Also, the presence of alumina in the melt increases the dissolution of $\mathrm{Pt}$, in contrast to silica. Only glasses $\mathrm{Ca}_{0.39}, \mathrm{Ca}_{10.23}, \mathrm{Ca}_{10.35}$, and $\mathrm{Ca}_{16.21}$ could be studied by XAFS spectroscopy because they were the most enriched in Pt (20-200 ppm Pt). However, it should be possible to carry out XAFS studies of glasses with even lower Pt concentrations in the near future because of the availability of higher X-ray fluxes on third generation synchrotron radiation sources.

\section{XANES spectroscopy}

The XANES spectrum for $\mathrm{Pt}^{4+}$ model compounds (Fig. 2, left) is characterized by a sharp, intense $\mathrm{Pt}_{\mathrm{III}}$-absorption edge. This absorption edge is caused by the excitation of an electron 


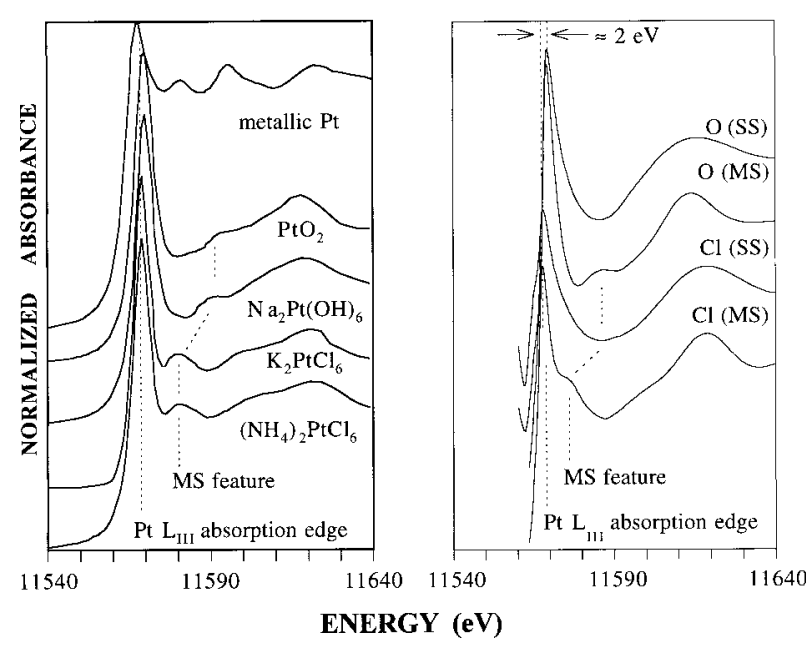

FigURE 2. (left) Experimental $\mathrm{Pt} \mathrm{L}_{\mathrm{III}}$-edge XANES spectra collected for various Pt-model compounds. (right) calculated XANES (FEFF7 code) for $\mathrm{PtO}_{6}$ and $\mathrm{PtCl}_{6}$ clusters showing the effect of $\mathrm{Pt}-\mathrm{O}$ and $\mathrm{Pt}-\mathrm{Cl}$ multiple-scattering paths near 3.7 and $4 \AA$ on the MS feature near 20 $\mathrm{eV}$ after the main absorption edge. Note also the change in the absorption edge position and intensity as a function of the Pt-redox state and nature of the ligands ( $\mathrm{O}$ vs. $\mathrm{Cl}$ ), as measured experimentally (e.g., left).

from the $2 \mathrm{p}_{3 / 2}$ core level to empty valence and continuum levels (see Horsley et al. 1982; Mansour et al. 1984). The intensity of the absorption edge has been directly related to the density of unoccupied d states (allowed transition from $2 p$ to $5 \mathrm{~d}$ levels). However, others attribute these features to multiplescattering effects of the ejected photoelectron wave from the central absorbing atom among its nearest and next-nearest neighbors (e.g., Natoli and Benfatto 1986). In using the FEFF7 multiple-scattering formalism to model the $\mathrm{Pt}_{\mathrm{III}}$-edge region, we have verified the appropriateness of the latter interpretation. The characteristics and origins for these edge features are presented below.

\section{The Pt $\mathrm{L}_{\mathrm{III}}$-edge crest}

The absorption edge is more intense for the $\mathrm{Pt}^{4+}$ model compounds considered than for metallic Pt. Also, the energy position of the absorption edge feature is shifted toward higher energies with increasing Pt-oxidation state by $\sim 2 \mathrm{eV}$ (Fig. 2, left). There is also a weaker but significant variation in the absorption edge and its intensity depending on the nature of the ligands $(\mathrm{O}$ vs. $\mathrm{Cl})$ around $\mathrm{Pt}^{4+}$ (Fig. 2, left). When $\mathrm{Pt}^{4+}$ has oxygen nearest neighbors (as in $\alpha-\mathrm{PtO}_{2}$ and $\mathrm{Na}_{2} \mathrm{Pt}(\mathrm{OH})_{6}$ model compounds), the absorption edge is more intense (sharper) and shifted by $\sim 2 \mathrm{eV}$ to higher energy values (Fig. 2, left) relative to $\mathrm{Pt}^{4+}$ with chlorine nearest neighbors [as in $\mathrm{K}_{2} \mathrm{PtCl}_{6}$ and $\left(\mathrm{NH}_{4}\right)_{2} \mathrm{PtCl}_{6}$ model compounds].

\section{MS feature}

In addition to the absorption edge, a feature located between 12 and $24 \mathrm{eV}$ above the maximum of the absorption edge is observed (labeled MS on Fig. 2, left) for $\mathrm{Pt}^{4+}$ model compounds. Its position depends on the type of ligand around the central Pt. In case of $\mathrm{Cl}$ first neighbors, the feature is shifted toward lower energy values when compared to Pt-oxide model compounds (10-12 eV shift). Based on ab-initio XANES calculations, we are able to assign this feature to MS effects within the coordination sphere of $\mathrm{Pt}^{+4}$, as explained below.

\section{Ab-initio XANES calculations}

These calculations (using the FEFF7 code, Rehr et al. 1992; Zabinsky et al. 1995) were undertaken for typical $\mathrm{PtO}_{6}$ and $\mathrm{PtCl}_{6}$ clusters (seven atoms) to ascertain the previous qualitative assignments of the XANES features (Fig. 2, right). The cluster structure information is taken from the model compounds $\mathrm{Na}_{2} \mathrm{Pt}(\mathrm{OH})_{6}$ and $\mathrm{K}_{2} \mathrm{PtCl}_{6}$. The FEFF7 code can be utilized to calculate XANES spectra for single-scattering events (such as that related to a $\mathrm{Pt} \leftrightarrow \mathrm{O}$ path of the excited photoelectron which corresponds to a single $\mathrm{O}$ backscatterer) as well as for multiple-scattering events (e.g., $\mathrm{O} \leftrightarrow \mathrm{Pt} \leftrightarrow \mathrm{O}$, involving several $\mathrm{O}$ backscatterers). MS paths up to $6 \AA$ in length were included in the XANES calculations for these simple $\mathrm{PtO}_{6}$ or $\mathrm{PtCl}_{6}$ clusters. Self-consistent Hedin-Lundqvist potentials were used (see Zabinsky et al. 1995), and the energy of the Fermi level was corrected by $+4 \mathrm{eV}$ to account for the +4 oxidation state of Pt. All spectra were shifted by $+25 \mathrm{eV}$ to correspond with the experimental monochromator energy calibration. All other FEFF7 parameters were set to their default values. For each cluster $\left(\mathrm{PtO}_{6}\right.$ and $\left.\mathrm{PtCl}_{6}\right)$, the XANES spectra were calculated assuming two models: first, single-scattering (SS) contributions only, and, second, the sum of single- and multiple-scattering contributions (Fig. 2, right).

Comparison of the ab-initio XANES spectra with the experimental spectra confirms that the experimental $\mathrm{Pt}_{\mathrm{III}}$-edge data can be accurately reproduced assuming SS and MS effects involving only the first shell of neighboring atoms around the central Pt. The MS feature located at $\sim 10-20 \mathrm{eV}$ above the absorption edge is observed only when MS paths are included in the calculation. Ab-initio calculations also suggest that this MS feature is affected in position and intensity by the nature of the ligands around $\mathrm{Pt}^{4+}$. For $\mathrm{Cl}$-first neighbors, its position is shifted to lower energies compared to that observed for Pt-O ligands (it is also less intense). In the FEFF7 calculation, this feature results from a $\mathrm{O} \leftrightarrow \mathrm{Pt} \leftrightarrow \mathrm{O}$ scattering path of the ejected photoelectron within the $\mathrm{PtO}_{6}$ cluster. This path has an effective length $\mathrm{R}$ of about $3.7 \AA$. For the $\mathrm{PtCl}_{6}$ cluster, the same type of MS contribution is detected but with a greater length $(\mathrm{R}=4.0 \AA)$, because of the larger ionic radius of $\mathrm{Cl}$ compared to $\mathrm{O}(\sim 1.7$ and $1.4 \AA$, respectively). Because the energy position of XANES features is correlated with $\mathrm{R}^{-2}$ (see Natoli and Benfatto 1986, among others), the MS feature for the $\mathrm{PtCl}_{6}$ cluster should therefore be located at a lower energy compared to that for $\mathrm{PtO}_{6}$, which is what we observe.

\section{XANES for the Pt-glasses}

For the Pt-glasses studied (Fig. 3), the Pt $\mathrm{L}_{\mathrm{III}}$-XANES spectra are similar to those observed for $\mathrm{Pt}^{4+}-\mathrm{O}$ model compounds $\left[\alpha-\mathrm{PtO}_{2}, \mathrm{Na}_{2} \mathrm{Pt}(\mathrm{OH})_{6}\right]$ : the $\mathrm{Pt} \mathrm{L}_{\mathrm{III}}$-absorption edge is intense and centered around $11569.5 \mathrm{eV}$. This suggests that $\mathrm{Pt}$ is mainly 


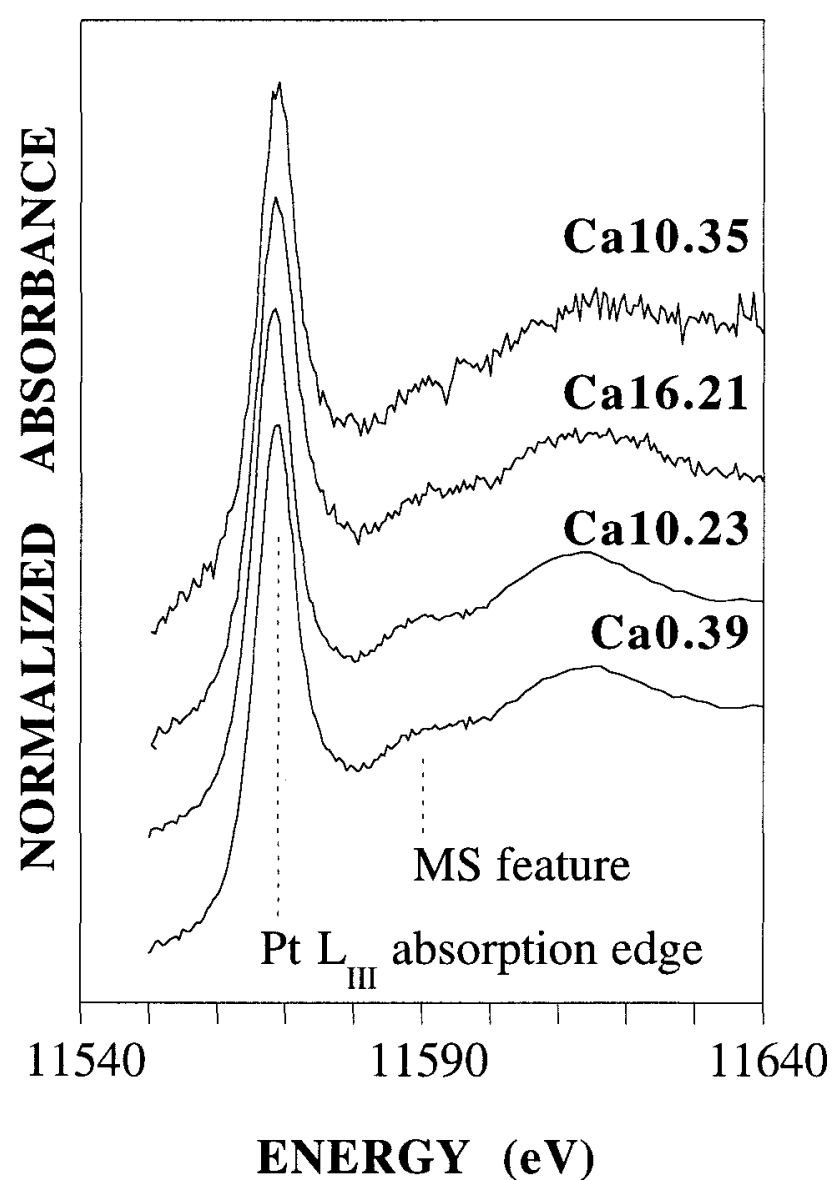

FIGURE 3. Experimental Pt- $\mathrm{L}_{\mathrm{III}}$ edge XANES spectra collected for the Pt-containing CAS glasses. The spectra are consistent with the presence of $\mathrm{Pt}^{4+}$ coordinated by six $\mathrm{O}$ atoms, as suggested by theoretical XANES calculations (cf. Fig. 2, left).

tetravalent in the glasses studied. No significant amounts of metallic Pt or any other reduced or highly oxidized Pt-species (such as $\mathrm{Pt}^{+}, \mathrm{Pt}^{2+}$, or $\mathrm{Pt}^{6+}$ ) were detected (indicating they are absent or present at concentrations less than 10 at $\%$ ). In addition, the MS feature located at $\sim 20 \mathrm{eV}$ above the absorption edge is observed, like in the $\mathrm{NaPt}(\mathrm{OH})_{6}$ and $\alpha-\mathrm{PtO}_{2}$ model compounds (Fig. 3).

\section{EXAFS spectroscopy}

The FT values for the model compounds (Fig. 4) show an intense contribution centered around $\sim 1.7 \AA$ [as in $\mathrm{NaPt}(\mathrm{OH})_{6}$ and $\left.\alpha-\mathrm{PtO}_{2}\right], \sim 2 \AA\left[\mathrm{K}_{2} \mathrm{PtCl}_{6}\right.$ and $\left.\left(\mathrm{NH}_{4}\right)_{2} \mathrm{PtCl}_{6}\right]$ and $\sim 3 \AA$ (metallic $\mathrm{Pt}$ ). In the FT values, distances are uncorrected for backscattering phase-shifts. This contribution is due to the presence of first neighbors around $\mathrm{Pt}(\mathrm{O}, \mathrm{Cl}$, or $\mathrm{Pt}$, respectively). The larger ionic radius of $\mathrm{Cl}$ compared to $\mathrm{O}$ causes the $\mathrm{Pt}-\mathrm{Cl}$ peak to shift to longer distances compared to Pt-O pairs. These model compounds show little evidence for next-nearest neighbors around Pt because of disorder effects (positional and thermal, see Brown et al. 1995).

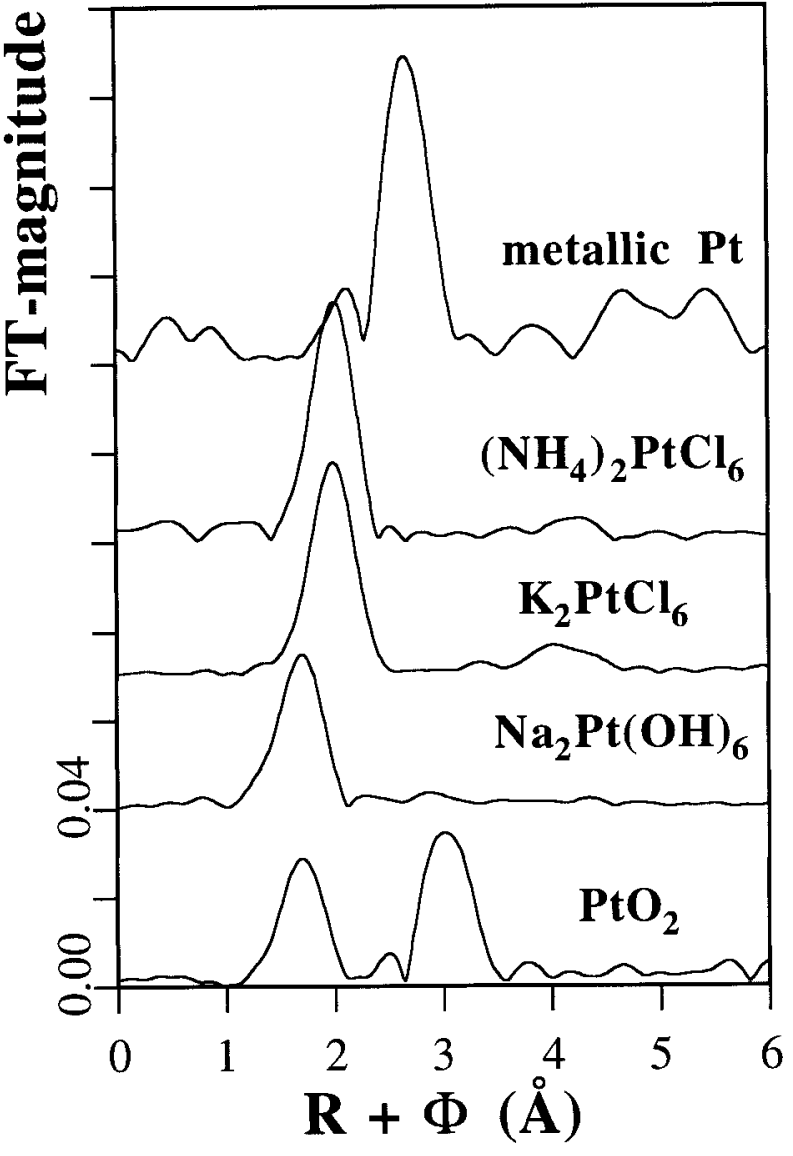

FigURE 4. FT of the $k^{3}$-weighted extended EXAFS spectra for the model compounds. Note the strong Pt-Pt correlation for metallic Pt near $3 \AA$ (in the FT, distances are uncorrected for backscattering phaseshifts).

The absence of Pt-Pt contributions near $\sim 3 \AA$ in the FT for the $\mathrm{Ca}_{0.39}$ and $\mathrm{Ca}_{10.23}$ glasses (Fig. 5, left) rules out the presence of significant amounts ( $<10 \%$ of the total Pt atoms) for metallic $\mathrm{Pt}$ in these samples. This result is in agreement with the XANES results (presence of an intense absorption edge shifted toward higher energy). In contrast, the FT values calculated from the EXAFS spectra of the glasses (Fig. 5, right) show an intense peak centered around $1.7 \AA$ (uncorrected for backscattering phase-shift). This contribution arises from $\mathrm{O}$ atoms first neighbors around $\mathrm{Pt}$, like in the $\mathrm{NaPt}(\mathrm{OH})_{6}$ model compound. Fitting of EXAFS oscillations for the $\mathrm{Ca}_{0.39}$ and $\mathrm{Ca}_{10.35}$ glasses gives $6.6 \pm 1$ oxygen atoms around $\mathrm{Pt}$ at an average Pt-O distance of 2.08-2.09 $\pm 0.02 \AA$ (Table 2). The $\mathrm{PtO}_{6}$ polyhedra show relatively little radial distortion (the anharmonic $\mathrm{C}_{3}$ parameters are nearly zero). The EXAFS-derived average Pt-O distance for the glasses studied is consistent with that observed for $\mathrm{Pt}^{4+} \mathrm{O}_{6}$ polyhedra in crystalline $\mathrm{NaPt}(\mathrm{OH})_{6}$ (Bandel et al. 1979). Some minor or trace amounts of other Pt-coordinations (4 and/or 5, if possible) are not excluded in these glasses, but sixfold coordinated $\mathrm{Pt}^{4+}$ is the dominant species. 

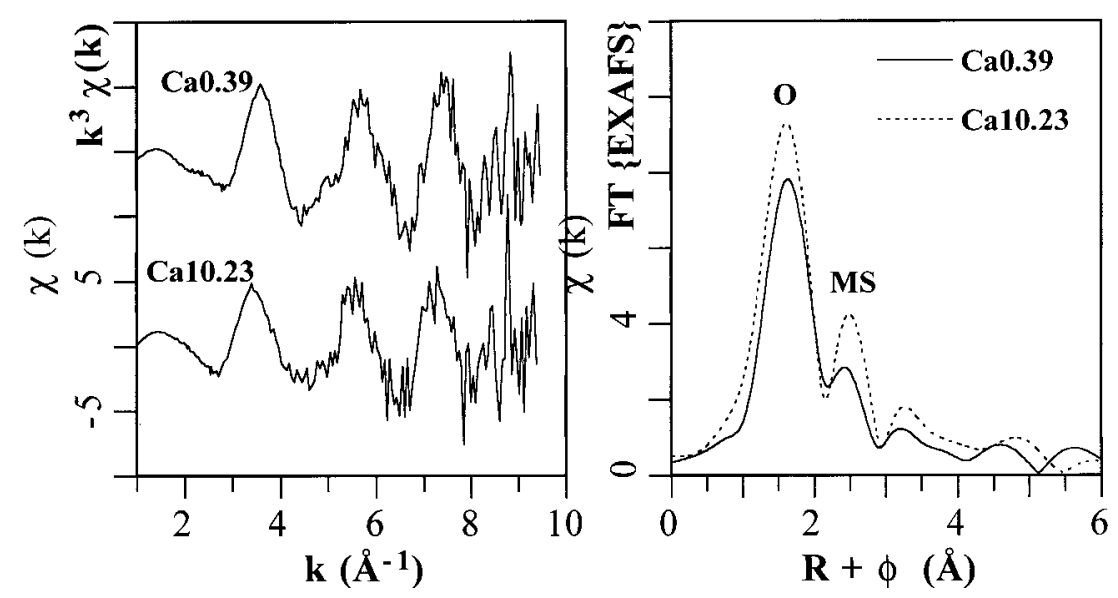

FiguRE 5. Normalized EXAFS (left) spectra and their FT values, (right) collected for the Pt-glasses $\mathrm{Ca}_{0.39}$ and $\mathrm{Ca}_{10.35}$ at the $\mathrm{Pt}$ $\mathrm{L}_{\mathrm{III}}$-edge. In these glasses, $\mathrm{Pt}$ is coordinated by six oxygen first neighbors. No clear evidence for next-nearest neighbors was detected in the experimental data (the peak near $2.8 \AA$ arises from multiple-scattering effects inside the $\mathrm{PtO}_{6}$ octahedron).
The peak near $2.5 \AA$ in the FT arises from MS effects within the $\mathrm{PtO}_{6}$ units (this peak disappears from the FT when the FT is calculated for a $k$-range starting above $k=4 \AA^{-1}$ ). No clear evidence for second-neighbor contributions ( $\mathrm{Pt}, \mathrm{Al}, \mathrm{Si}$, or $\mathrm{Ca}$ ) around the $\mathrm{PtO}_{6}$ polyhedra was detected in either glass. EXAFS spectra for the two other glasses $\left(\mathrm{Ca}_{10.23}\right.$ and $\left.\mathrm{Ca}_{16.21}\right)$ were not collected because the signal-to-noise ratio is too low and because their XANES spectra are similar to those collected for the two other glasses investigated in this study $\left(\mathrm{Ca}_{0.39}\right.$ and $\left.\mathrm{Ca}_{10.35}\right)$.

\section{DISCUSSION}

The structural and oxidation state information derived from XANES spectra of the Pt-containing glasses in the $\mathrm{CaO}-\mathrm{Al}_{2} \mathrm{O}_{3}$ $\mathrm{SiO}_{2}$ ternary is consistent with that derived from the EXAFS spectra and suggests the presence of $\mathrm{Pt}^{4+} \mathrm{O}_{6}$ polyhedra. No significant amounts $\left(<10\right.$ at\%) of $\mathrm{Pt}^{0}$ and/or $\mathrm{Pt}^{2+}$ were found in these glasses. Thus, the solubility of Pt is clearly favored under oxidizing conditions in the $\mathrm{Pt}^{4+}$ form, which is similar to the correlation between solubility and oxidation state observed for other cations with variable oxidation states (e.g., Mo, U, Veal et al. 1987). These results are consistent in part with the electrochemical information derived for Pt in similar glasses (Dablé et al. 1996), whereas $\mathrm{Pt}^{4+}$ is found to be a major Pt-species in CAS melts prepared under moderately oxidizing conditions. These experiments also suggest the presence of large amounts of $\mathrm{Pt}^{6+}$ in the most calcic glasses of this ternary system synthesized under oxidizing conditions. However, our direct XAFS results do not confirm this suggestion. Also, no evidence for $\mathrm{Pt}^{2+}$ was found in any of the glasses studied, as previously suggested from solubility experiments (Borisov et al. 1996). Our direct spectroscopic results therefore suggest that the interpretation of solubility information for Pt as a function of the oxygen fugacity is not straightforward. A slope of $\sim+1 / 2$ in the plot of the Pt-concentration in glasses as a function of oxygen fugacity during synthesis may not always be indicative of $\mathrm{Pt}^{2+}$. Other factors, such as the formation of a passivation layer around Pt particles, may influence the slope in these plots (Amossé et al. 1990; Dablé et al. 1996; see also Capobianco et al. 1994).

\section{Medium-range environment of $\mathbf{P t}^{4+}$}

Unfortunately, no information can be derived from XAFS spectra about the medium-range structure of $\mathrm{Pt}^{4+}$ in these glasses because there is no clear contribution in the FT above $3 \AA$. The lack of second-neighbor information in the XAFS spectra of Pt in these glasses is in contrast to the XAFS spectra of other cations such as $\mathrm{Zr}^{4+}$ and $\mathrm{Ti}^{4+}$ in similar glasses which show clear second-neighbor contributions in their FT values (Farges et al. 1991; Farges 1999). This lack of information may be due to a complex medium-range structural environment around $\mathrm{Pt}^{4+}$ in the CAS glasses being considered. Data collection near $4 \mathrm{~K}$ in these glasses can be performed to minimize the effects of thermal disorder on XAFS spectra (and therefore can promote contributions from second neighbors such as weakly bonded network modifiers which should exhibit significant thermal motion even at room temperature). However, it was not technically feasible to collect low temperature XAFS data with the currently available XAFS spectrometers and sample cryostats, given the very low Pt concentrations in these CAS glasses. Also, most of the available XAFS data for highly charged cations in silicate glasses show that collecting data at very low temperatures does not result in a dramatic improvement in EXAFS spectra (i.e., there is little improvement in resolution of second-neighbor frequencies). This observation suggests that the lack of second-neighbor contributions in the Pt $\mathrm{L}_{\mathrm{III}}$-EXAFS

TABLE 2. EXAFS-derived anharmonic structural parameters for the glasses studied.

\begin{tabular}{|c|c|c|c|c|c|}
\hline \multirow[b]{2}{*}{ Glass } & \multicolumn{4}{|c|}{ Oxygen shell } & \multirow[t]{2}{*}{$\chi^{2 *}$} \\
\hline & $\mathrm{N}$ & $\begin{array}{c}\mathrm{R} \\
(\AA) \\
\end{array}$ & $\begin{array}{c}\mathrm{S}^{2} \\
\left(\AA^{2}\right)\end{array}$ & $\begin{array}{c}\mathrm{C}_{3} \\
\left(\AA^{3}\right)\end{array}$ & \\
\hline $\mathrm{Ca}_{0.39}$ & 6.6 & 2.09 & 0.009 & 0.0020 & 0.057 \\
\hline $\mathrm{Ca}_{10.35}$ & 6.7 & 2.08 & 0.011 & 0.0015 & 0.063 \\
\hline
\end{tabular}

$\begin{array}{llll}\text { Error }( \pm) & 1 & 0.02 & 0.002\end{array}$

Notes: $\mathrm{N}, \mathrm{R}, \sigma^{2}$, and $\mathrm{C}_{3}$ are, respectively, the number of neighbors, the average Pt-O distance, the absolute Debye-Waller-type factor, and the third-order anharmonic cumulant at $293 \mathrm{~K}$. 
spectra of the CAS glasses is more likely related to a high degree of positional disorder in the medium-range environment around Pt.

The lack of discernible second neighbors around $\mathrm{Pt}$ in the CAS glasses may therefore be related to a preferential connection of the $\mathrm{Pt}^{4+} \mathrm{O}_{6}$ units to network modifiers (Ca) instead of network formers $(\mathrm{Si}, \mathrm{Al})$. Also, $\mathrm{Pt}^{4+}$ is found mostly in oxide compounds, with very few Pt-silicates known. The FT of $\mathrm{Na}_{2} \mathrm{Pt}(\mathrm{OH})_{6}$ (Fig. 4) is a good example of the presence of weakly bound second-neighbor cations around Pt on the Pt $\mathrm{L}_{\mathrm{III}}$-EXAFS spectrum; in this compound, Na second neighbors could not be detected because of their significant thermal and positional disorder around Pt.

\section{Bond-valence models}

To test the hypothesis that $\mathrm{Pt}$ in the CAS glasses has $\mathrm{Ca}$ second neighbors we can use a bond-valence model to examine different types of second-neighbor environments around the $\mathrm{PtO}_{6}$ polyhedra. This model (see Farges et al. 1991) is based on the idea that Pauling's second rule (Pauling 1929) should be valid for oxide glasses. The Pt-O bond provides $\sim 0.7$ valence units (v.u.) $\left({ }^{4+} / 6 \sim 0.7\right.$ v.u.). To calculate $\mathrm{Ca}-\mathrm{O}, \mathrm{Al}-\mathrm{O}$, and $\mathrm{Si}-\mathrm{O}$ bond valences, we must know the coordination numbers of $\mathrm{Ca}$, $\mathrm{Al}$, and Si cations in such glasses (reviews of such data can be found in Brown et al. 1995 and Stebbins 1995). These reviews suggests that $\mathrm{Si}$ and $\mathrm{Ca}$ are mostly likely fourfold and sixfold coordinated, respectively. The bond valences for ${ }^{\left[{ }^{[V}\right]} \mathrm{Si}-\mathrm{O}$ and ${ }^{[\mathrm{VI}]} \mathrm{Ca}-\mathrm{O}$ bonds are around 1.0 and $0.3 \pm 0.05$ v.u., respectively. For Al-O bonds, the bond valence is about 0.75 because the main Al-coordination in these glasses is fourfold (Engelhardt et al. 1985; Poe et al. 1994; Stebbins 1995) in agreement with thermodynamic and Raman scattering information (Neuville et al. 1994). Higher Al-coordinations (five or six) have been reported in these glasses (Poe et al. 1994; Giuli et al. 1995) but at minor levels (no more than $\sim 20 \%$ of the total $\mathrm{Al}$ ). However, in the medium-range environment around $\mathrm{Pt}$ these higher $\mathrm{Al}$ coordinations cannot be excluded because ${ }^{[\mathrm{V}]} \mathrm{Al} /{ }^{[\mathrm{VI}]} \mathrm{Al}$, if present, could be more abundant than $\mathrm{Pt}^{4+}$ in these glasses.

Based on the assumptions stated above, the bond-valence model can be used to derive two plausible structural arrangements around $\mathrm{O}$ atoms of a $\mathrm{PtO}_{6}$ polyhedron (Fig. 6). One possible structural arrangement involves one $\mathrm{Pt}$, one $\mathrm{Ca}$, and one $\mathrm{Si}$ bonded to $\mathrm{O}$ (see $\mathrm{O}_{1}$ atoms in Fig. 6). The valence balance around $\mathrm{O}_{1}$ atoms $(0.7+0.3+1.0=2.0$ v.u. $)$ satisfies Pauling's electrostatic valence principle at room temperature. The $\mathrm{O}_{1} \mathrm{O}$ atoms are threefold-coordinated and non-bridging (NBO), and the presence of some $\mathrm{Si}$ is required in the glasses in order to achieve valence balance. When $\mathrm{Al}$ replaces $\mathrm{Si}$ (see $\mathrm{O}_{2}$ atoms in Fig. 6), two $\mathrm{Ca}$ atoms are required around oxygen to compensate for the deficit of bond valence due to this substitution ( 0.7 $+2 \times 0.3+0.75=2.05$ v.u.). The $\mathrm{O}_{2}$ atoms are fourfold coordinated NBOs and require ${ }^{[\mathrm{IV}]} \mathrm{Al}$ for valence balance. Other plausible bond-valence models can be postulated with ${ }^{[\mathrm{V}]} \mathrm{Al}$ or ${ }^{[\mathrm{VI}]} \mathrm{Al}$ in the second-neighbor coordination shell of $\mathrm{Pt}^{4+}$ if we assume that these $\mathrm{Al}$ coordinations are present at significant levels in these CAS glasses. For example, fourfold coordinated NBOs are possible bonded to two $\mathrm{Ca}$ and one ${ }^{[\mathrm{V}]} \mathrm{Al}$ or bonded to one $\mathrm{Ca}$ and two ${ }^{[\mathrm{VIl}} \mathrm{Al}\left(\mathrm{O}_{3}\right.$ and $\mathrm{O}_{4}$ atoms, respectively, in Fig. 6).

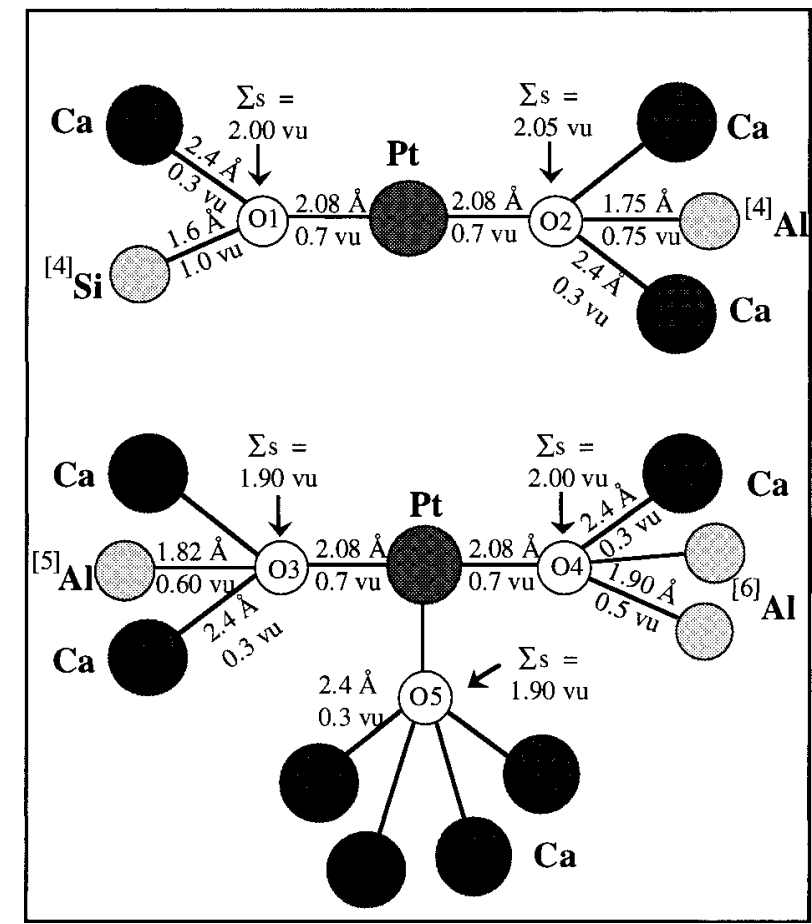

FigURE 6. Bond-valence model of the local structure around $\mathrm{Pt}^{4+}$ in the oxide glasses studied. $\mathrm{Pt}^{4+}$ must bond to non-bridging $\mathrm{O}$ atoms which may be threefold or fourfold coordinated, respectively: ${ }^{\left[{ }^{[I I]}\right.} \mathrm{O}_{1}$ atoms are surrounded by one ${ }^{[\mathrm{VI}]} \mathrm{Ca}$ and one ${ }^{[\mathrm{IV}]} \mathrm{Si}$ (less likely because $\mathrm{Pt}$ solubility is not high in melts with Si-rich compositions); ${ }^{\left[{ }^{[V]}\right]} \mathrm{O}_{2}$ atoms have two ${ }^{[\mathrm{VI}]} \mathrm{Ca}$ and one ${ }^{[\mathrm{IV}]} \mathrm{Al}$ nearest neighbors. Two other types of $\mathrm{O}$ atoms bonded to ${ }^{[\mathrm{V}]} \mathrm{Al}$ and/or ${ }^{[\mathrm{VI}]} \mathrm{Al}\left(\mathrm{O}_{3}\right.$-type and $\mathrm{O}_{4}$-type) are also plausible. Finally $\mathrm{O}_{5}$-type atoms, bonded only to ${ }^{[\mathrm{VI}]} \mathrm{Ca}$, may be the most common type of $\mathrm{NBO}$ around $\mathrm{Pt}^{4+}$ in CAS glasses.

Finally, a model with only network modifiers $(\mathrm{Ca})$ bonded to the $\mathrm{O}$ atoms coordinating $\mathrm{Pt}$ (through $\mathrm{O}_{5}$ atoms) is also possible. This type of second-neighbor environment around $\mathrm{Pt}$ is found in the model compound $\mathrm{Na}_{2} \mathrm{Pt}(\mathrm{OH})_{4}$. Medium-range structural environments around $\mathrm{Pt}$ that are combinations of the models presented here are also possible.

\section{A structural model for the solubility of $\mathrm{Pt}^{4+}$ in oxide glasses}

The presence of $\mathrm{O}_{1}$-type $\mathrm{O}$ atoms around $\mathrm{Pt}$ is less likely because Pt-contents in the CAS glasses increase with decreasing $\mathrm{SiO}_{2}$ contents, suggesting little structural correlation between $\mathrm{Pt}$ and $\mathrm{Si}$ in these systems, as previously stated. Corner sharing of $\mathrm{PtO}_{6}$ octahedra and $\mathrm{AlO}_{4}$ tetrahedra may be a more likely type of linkage (models involving $\mathrm{O}_{2}$-type $\mathrm{O}$ atoms) because ${ }^{[\mathrm{IV}]} \mathrm{Al}$ is by far the most abundant $\mathrm{Al}$-species in glasses/ melts of this ternary system (alternative models involving ${ }^{[\mathrm{V}]} \mathrm{Al}$ and ${ }^{[\mathrm{VI}]} \mathrm{Al}$ are also possible through $\mathrm{O}_{3}$ - and $\mathrm{O}_{4}$-type $\mathrm{O}$ atoms). $\mathrm{O}_{2}$-type $\mathrm{O}$ atoms around ${ }^{[\mathrm{VI}]} \mathrm{Pt}^{4+}$ would require $\sim 6 \mathrm{Al}$ and $12 \mathrm{Ca}$ in the medium-range environment of Pt. This large number of weakly bonded $\mathrm{Ca}$ atoms, which can have a relatively wide range of $\mathrm{Ca}-\mathrm{O}$ distances and $\mathrm{Ca}-\mathrm{O}-\mathrm{Pt}$ angles, should result in a disordered medium-range structural environment around $\mathrm{Pt}$. This suggestion is consistent with the lack of detectable sec- 
ond neighbors in the Pt $\mathrm{L}_{\mathrm{III}}$ edge EXAFS for these glasses. The same conclusions can be reached for $\mathrm{O}_{5}$-type $\mathrm{O}$ atoms. Therefore, previous qualitative models of the medium-range environment of $\mathrm{Pt}$, which suggest " $\mathrm{CaPtO}_{\mathrm{x}}$ " units based on solubility and electrochemical measurements (Antonenkova et al. 1989; Dablé 1996), are consistent with the bond-valence models shown in Figure 6.

In conclusion, the solubility of $\mathrm{Pt}^{4+}$ in $\mathrm{CaO}-\mathrm{Al}_{2} \mathrm{O}_{3}-\mathrm{SiO}_{2}$ glasses/melts examined in this study is consistent with the presence of a large number of network modifiers, such as $\mathrm{Ca}$, around Pt. Also, some oxygen dissolved in the melt (in equilibrium with the atmosphere of the furnace) is required to favor the oxidation of metallic Pt (Dablé 1996). Network modifiers (Me) with similar Me-O bond valences ( 0.3), as well as relatively small alkali cations (such as $\mathrm{Na}$ ), should also promote Pt-solubility. If we assume that CAS glasses and melts contain two types of percolation domains (one consisting primarily of the network formers $\mathrm{Si}$ and $\mathrm{Al}$, and one consisting primarily of the network modifier Ca (Eckserley et al. 1988; Gaskell et al. 1992) then $\mathrm{Pt}^{4+}$ should be strongly partitioned into the Ca-rich domains, as $\mathrm{CaPt}^{4+} \mathrm{O}_{6}$-type units.

\section{ACKNOWLEDGMENTS}

The authors thank Hatten Yoder and Bjorn Mysen for support and discussion, Marc Benedetti (CNRS, Paris) for assistance with data collection, and Maurel (Service d'Analyses des Roches et Minéraux, CRPG-CNRS Nancy) for Pt analyses of the glasses. This work was supported by the GDR Métallogénie (CNRS, FF) and NSF grant EAR-9305028 (G.E.B.). Comments from Paul McMillian and Robert Mayanovic greatly improved the manuscript. The Stanford Synchrotron Radiation Laboratory is supported by DOE, Office of Basic Energy Sciences, and NIH, Biotechnology Resource Program, Division of Research Resources.

\section{REFERENCES CITED}

Amossé, J., Piboule, M., and Allibert, M. (1990) Experimental study of the solubility of platinum and iridium in basic melts; implications for the differentiation of platinum-group elements during magmatic processes. Chemical Geology, 81, $45-53$.

Antonenkova, N.D., Bozhenov, A.A., Volkova, R.M., and Kuznetsova, M.G. (1989) Investigation of the platinum-glass contact zone. Izvestia Akademii Nauk SSSR Metally, 4, 188-192.

Azif, E., Pichavant, M., and Auge, T. (1996) Solubility of Pt and Pd in Dio-An melts; methodology and effects of $f_{\mathrm{O} 2}$ and addition of iron. Terra Abstracts, 8 , (Suppl. 1), 4.

Bandel, G., Müllner, M., and Trömel, M. (1979) Die Kristallstruktur von $\mathrm{Na}_{2} \mathrm{Pt}(\mathrm{OD})_{6}$ Zeitschrift für anorganische Chemie, 453, 5-8.

Borisov, A., Palme, H., and Spettel, B. (1996) The solubility of Pt in silicate melts. Experiments under oxidizing conditions. Max Plack Institut für Chemie, Mainz, Germany (quoted in Dablé, 1996, p. 46).

Brown, G.E. Jr., Farges, F., and Calas, G. (1995) X-ray scattering and X-ray spectroscopy studies of silicate melts. In Mineralogical Society of America Reviews in Mineralogy, Vol. 32, p. 317-410.

Capobianco, C.J., Hervig, R.L., and Drake, M.J. (1994) Experiments on crystal/ liquid partitioning of $\mathrm{Ru}, \mathrm{Rh}$ and $\mathrm{Pd}$ for magnetite and hematite solid solutions crystallized from silicate melt. Chemical Geology, 113, 23-43.

Crozier, E.D., Rehr, J.J., and Ingalls, R. (1988) Amorphous and liquid systems. In D.C. Koningsberger and R. Prins, Eds., X-ray absorption. Principles, applications, techniques of EXAFS, SEXAFS and XANES, Chemical Analysis, vol. 92, pp. 373-442. Wiley, New York.

Dablé, P.J-M. R. (1996) Etude thermodynamique d la solubilité du platine et du rhodium dans les oxydes liquides. Thèse, INP Grenoble, 172 p. (in French)

Eckersley, M.C., Gaskell, P.H., Barnes, A.C., and Chieux, P. (1988) Structural ordering in a calcium silicate glass. Nature, 335, 525-527.

Engelhardt, G., Nofz, M., Forkel, K., Wishmann, F.G., Mägi, M., Samosen, A., and
Lippmaa, E. (1985) Structural studies of calcium aluminosilicate glasses by high resolution solid state ${ }^{29} \mathrm{Si}$ and ${ }^{27} \mathrm{Al}$ magic angle spinning nuclear magnetic resonance. Physics and Chemistry of Glasses, 26, 157-165.

Fairbairn, H.W. and Schairer, J.F. (1952) A test of the accuracy of chemical analysis of silicate rocks. American Mineralogist, 37, 744-757.

Farges, F. (1999) A Ti K-edge EXAFS study of the medium range environment around Ti in oxide glasses. Journal of Non-Crystalline Solids, 244, 25-33.

Farges, F., Ponader, C.W., and Brown, G.E. Jr. (1991) Local environment around incompatible elements in silicate glass/melt systems. $\mathrm{I}: \mathrm{Zr}$ at trace levels. Geochimica et Cosmochimica Acta, 55, 1563-1574.

Gaskell, P.H., Zhao, J., Calas, G., and Galoisy, L. (1992) The structure of mixed cation oxide glasses. In L.D. Pye, W.C. LaCourse, H.J. Stevens, Eds., The Physics of Non-Crystalline Solids, p. 53-58. Taylor and Francis, London.

Ginther, R.J. (1971) The contamination of glass by platinum. Journal of Non-Crystalline Solids, 6, 294-306.

Giuli, G., Romano, C., Courtial, P., Dingwell, D.B., Mottana, A., and Marcelli, C. (1995) X-ray absorption evidence for variable coordination of $\mathrm{Al}$ in melts along the join $\mathrm{Ca}_{3} \mathrm{Al}_{2} \mathrm{O}_{6}-\mathrm{SiO}_{2}$. EOS, 76, F660 (abstract, AGU Fall Meeting).

Higby, P.L., Ginther, R.J., Aggarwal, I.D., and Friebele, E.J. (1990) Glass formation and thermal properties of low-silica calcium aluminosilicate glasses. Journal of Non-Crystalline Solids, 126, 209-215.

Horsley, J.A. (1982) Relationships between the area of $\mathrm{L}_{23} \mathrm{X}$-ray absorption edge resonances and the $\mathrm{d}$ orbital occupancy in compounds of platinum and iridium. Journal of Chemical Physics, 76, 1451-1458.

Kelm, M. and Oser, B. (1991) The platinum metals in HLLW-glass products. Materials Research Society Symposium Proceedings, 257, 177-183.

Mansour, A.N., Cook, J.W., and Sayers, D.E. (1984) Quantitative technique for the determination of the number of unoccupied d-electron states in a platinum catalyst using the $\mathrm{L}_{2,3} \mathrm{X}$-ray absorption edge spectra. Journal of Chemical Physics, $88,2330-2334$.

Natoli, C.R. and Benfatto, M. (1986) A unifying scheme of interpretation of X-ray absorption spectra based on multiple scattering theory. Journal de Physique, 47 C8, 11-23.

Neuville, D.R. (1992) Etude des propriétés thermodynamiques et rhéologiques des silicates fondus. Thèse de l'université Paris 7, 270 pp (in French).

Neuville, D.R., Mysen, B.O., and Richet, P. (1994) Raman spectroscopy, viscosity and configurational entropy in the $\mathrm{SiO}_{2}-\mathrm{Al}_{2} \mathrm{O}_{3}-\mathrm{CaO}$ system. Eos, Transactions of the American Geophysical Union, 74, 350 (abstract).

Pacaud, F., Fillet, C., and Jacquet-Francillon, N. (1991) Effects of platinoïds on French LWR reference glass properties. Material Research Society Symposium Proceedings, 257, 161-168.

Pauling, L. (1929) The principles determining the structure of complex ionic crystals. Journal of the American Chemical Society, 51, 1010-1026.

Poe, B., McMillan, P.F., Coté, B., Massiot, D., and Coutures, J.-P. (1994) Structure and dynamics in calcium aluminate liquids: high-temperature ${ }^{27} \mathrm{Al} \mathrm{NMR}$ and Raman spectroscopy. Journal of the American Ceramic Society, 77, 1832-1838.

Rehr, J.J., Albers, R.C., Natoli, C.R., and Stern, E.A. (1986) New high-energy approximation for X-ray-absorption near-edge structure. Physical Review B, 34, $4350-4353$.

Rehr, J.J., Zabinsky, Z.I., and Albers, R.C. (1992) High-order multiple scattering calculations of X-ray-absorption fine structure. Physical Review Letters, 69 , $3397-4000$.

Siegel, S., Hoelstra, H.R., and Tani, B.S. (1969) The crystal structure of beta-platinum dioxide. Journal of Inorganic and Nuclear Chemistry, 31, 3803-3807.

Stebbins, J.F. (1995) Dynamics and structure of silicate and oxide melts: nuclear magnetic resonance studies. In Mineralogical Society of America Reviews in Mineralogy, 32, 191-246.

Takazawa, H., Ohba, S., and Saito, Y. (1984) Electron density distribution in crystals of $\mathrm{K}_{2}\left[\mathrm{MCl}_{6}\right](\mathrm{M}=\mathrm{Re}, \mathrm{Os}, \mathrm{Pt})$ and $\mathrm{K}_{2}\left[\mathrm{PtCl}_{4}\right]$ at $120 \mathrm{~K}$. Acta Crystallographica B, 46, 166-174.

Veal, B.W., Mundy, J.N., and Lam, D.J. (1987) Actinides in silicate glasses. In A.J. Freeman, and G.H. Lander Eds., Handbook on the Physics and Chemistry of the Actinides, Vol. V, p. 271-309. North Holland, Amsterdam.

Winterer, M. (1996) The XAFS package. Proceedings of the 9th International Conference on X-ray Absorption Fine Structure (XAFS VI, Grenoble), 144.

Zabinsky, S.I., Rehr, J.J., Ankudinov, A., Albers, R.C., and Eller, M.J. (1995) Multiple scattering calculations of X-ray absorption spectra. Physical Review B, $52,2995-3009$.

MANUSCRIPT RECEIVED AUGUST 3, 1998

MANUSCRIPT ACCEPTED JUNE 9, 1999

PAPER HANDLED BY WILLIAM A. BASSETT 